\title{
Supporting Information for Rheological Characterization of Polymeric Frustrated Lewis Pair Networks
}

Utku Yolsal, a,b Meng Wang, ${ }^{a}$ John R. Royer ${ }^{\mathrm{c}}$ and Michael P. Shaver ${ }^{*, a, b}$

a School of Chemistry, Joseph Black Building, David Brewster Road, University of Edinburgh, Edinburgh, EH9 3FJ, UK

${ }^{\mathrm{b}}$ School of Materials, Oxford Road, University of Manchester, Manchester, UK, M13 9PL

c School of Physics and Astronomy, King's Buildings, Peter Guthrie Tait Road, University of Edinburgh, Edinburgh, EH9 3FD, UK 


\section{Section A: Analytical Characterization}

- Copolymers

Poly (sty-co-LA)s and poly(sty-co-LB)s, see our previous publication. ${ }^{1}$

$\operatorname{Poly}(M M A-\operatorname{co}-L A) s$

${ }^{1} \mathrm{H}$ NMR $\left(\mathrm{CDCl}_{3}, 400 \mathrm{MHz}\right), \delta=0.80-2.70(\mathrm{~m}, \mathrm{br}), 3.65$ (br) 7.90-6.30 ppm (m, br); ${ }^{11} \mathrm{~B}$ NMR $(\mathrm{CDCl} 3,128 \mathrm{MHz}) \delta=68.6 \mathrm{ppm}$

$\operatorname{Poly}(M M A-\operatorname{co}-L B) s$

${ }^{1} \mathrm{H} \mathrm{NMR}\left(\mathrm{CDCl}_{3}, 400 \mathrm{MHz}\right), \delta=0.80-2.70$ (m, br), 3.65 (br) 7.90-6.30 ppm (m, br); ${ }^{31} \mathrm{P}$ NMR $\left(\mathrm{CDCl}_{3}, 162 \mathrm{MHz}\right) \delta=-22.5 \mathrm{ppm}$

- 4-Phenyl-dimesitylphosphine

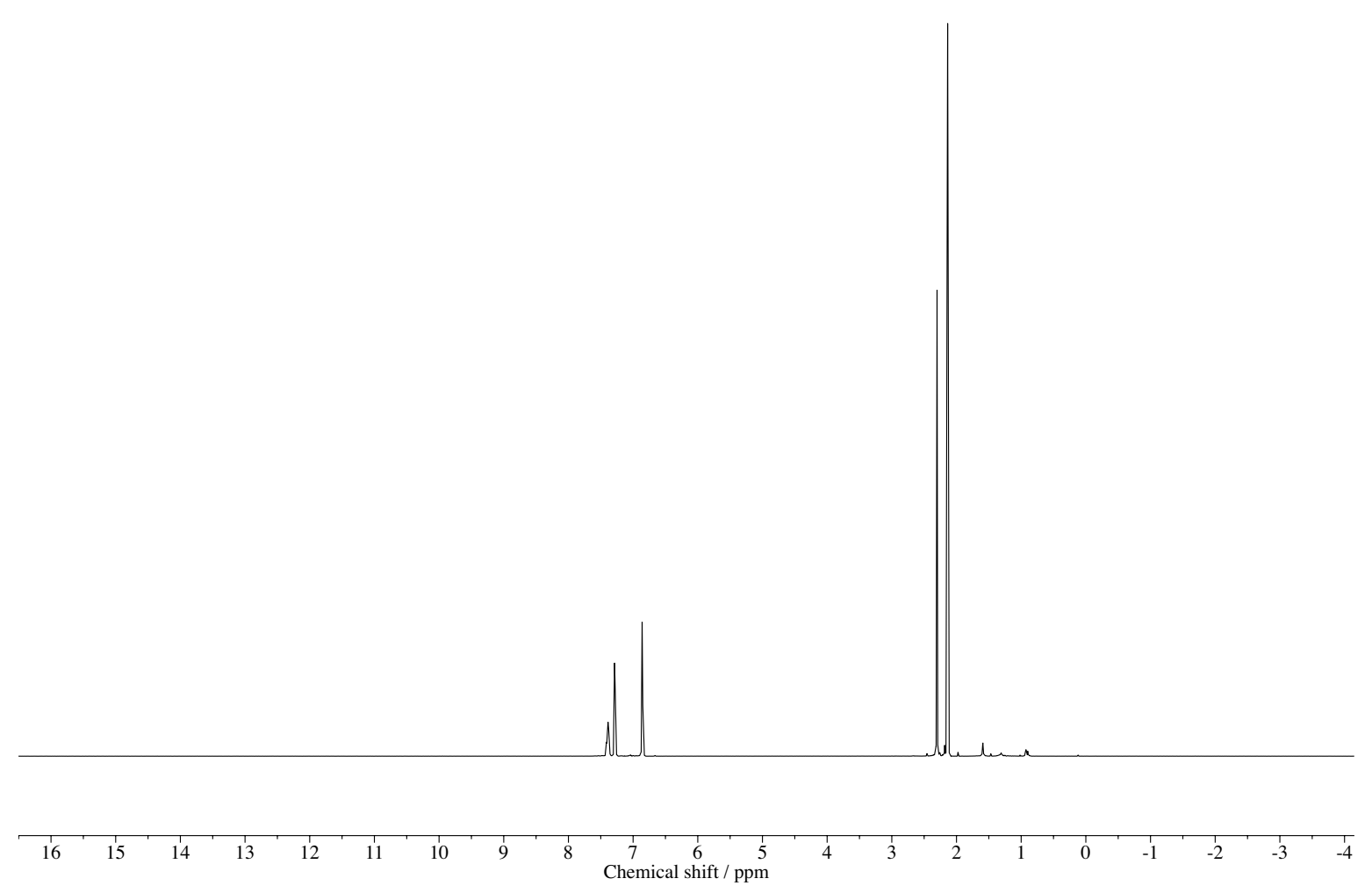

Figure S1: ${ }^{1}$ H NMR spectrum of 4-phenyl-dimesitylphosphine. 


\section{${ }^{31}$ P NMR:}

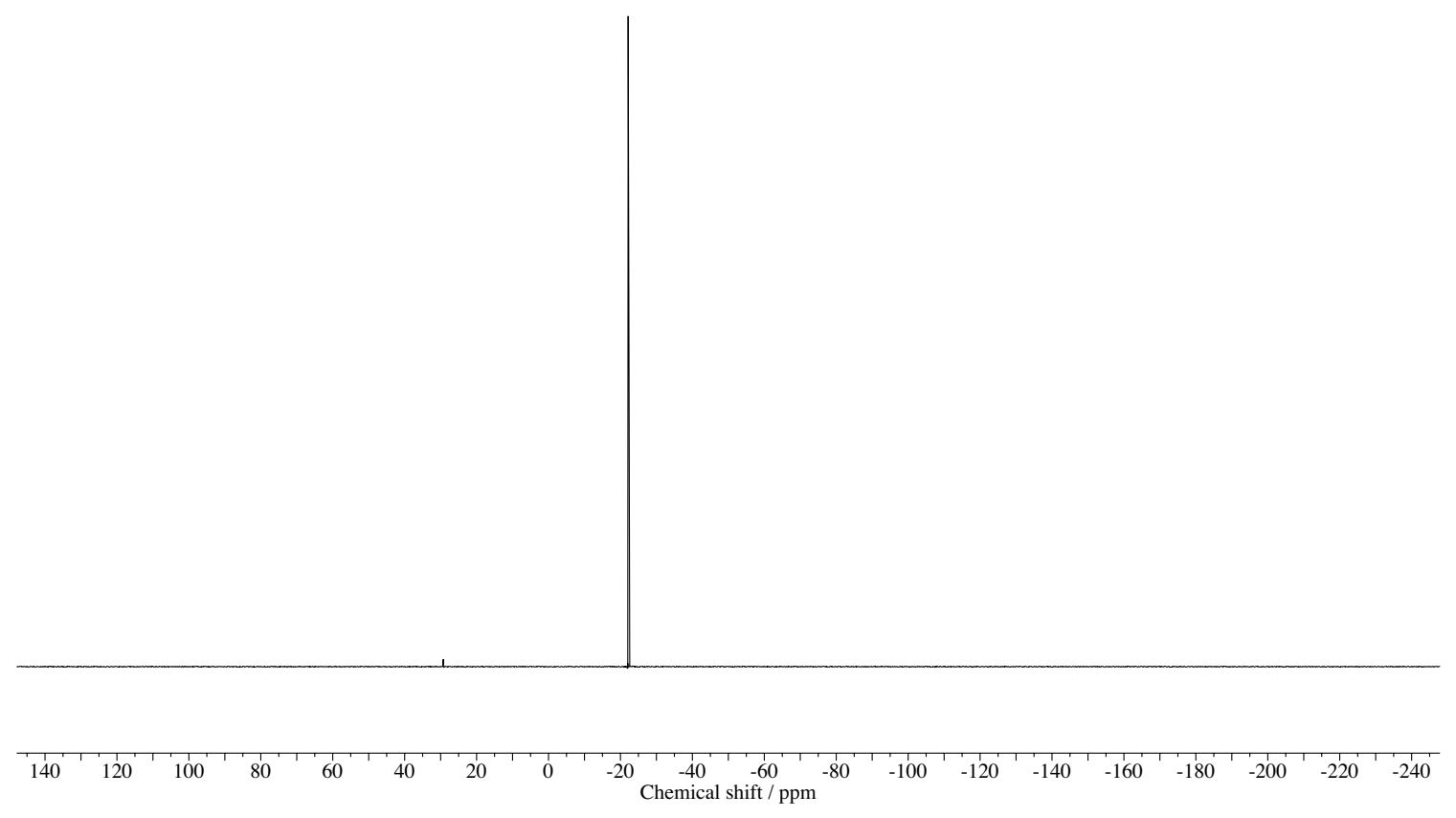

Figure S2: ${ }^{31} \mathrm{P}$ NMR spectrum of 4-phenyl-dimesitylphosphine.

Yield: 1.60 g, $40.6 \%$ m.p. $104-107^{\circ} \mathrm{C}$

${ }^{1} \mathrm{H}$ NMR (400 MHz, $\left.\mathrm{CDCl}_{3}\right), \delta$ 7.44-7.34 (m, 2H), 7.33-7.23 (m, 3H) $6.86(\mathrm{~d}, \mathrm{~J}=2.9 \mathrm{~Hz}, 4 \mathrm{H})$, $2.30(\mathrm{~s}, 6 \mathrm{H}), 2.14(\mathrm{~s}, 12 \mathrm{H})$.

${ }^{13} \mathrm{C} \mathrm{NMR}\left(126 \mathrm{MHz}, \mathrm{CDCl}_{3}\right) \delta 143.0(\mathrm{~d}, \mathrm{~J}=15.6 \mathrm{~Hz}), 138.2,137.8(\mathrm{~d}, \mathrm{~J}=12.0 \mathrm{~Hz}), 133.8(\mathrm{~d}, \mathrm{~J}$

$=22.1 \mathrm{~Hz}), 130.3(\mathrm{~d}, \mathrm{~J}=18.9 \mathrm{~Hz}), 130.1(\mathrm{~d}, \mathrm{~J}=3.5 \mathrm{~Hz}), 128.2(\mathrm{~d}, \mathrm{~J}=6.8 \mathrm{~Hz}), 127.90,23.16(\mathrm{~d}, \mathrm{~J}$ $=16.0 \mathrm{~Hz}), 21.06$.

${ }^{31} \mathrm{P}$ NMR (162 MHz, $\left.\mathrm{CDCl}_{3}\right), \delta-22.1$. 


\section{Section B: Determination of dn/dc for the poly(MMA-co-LB) 2}

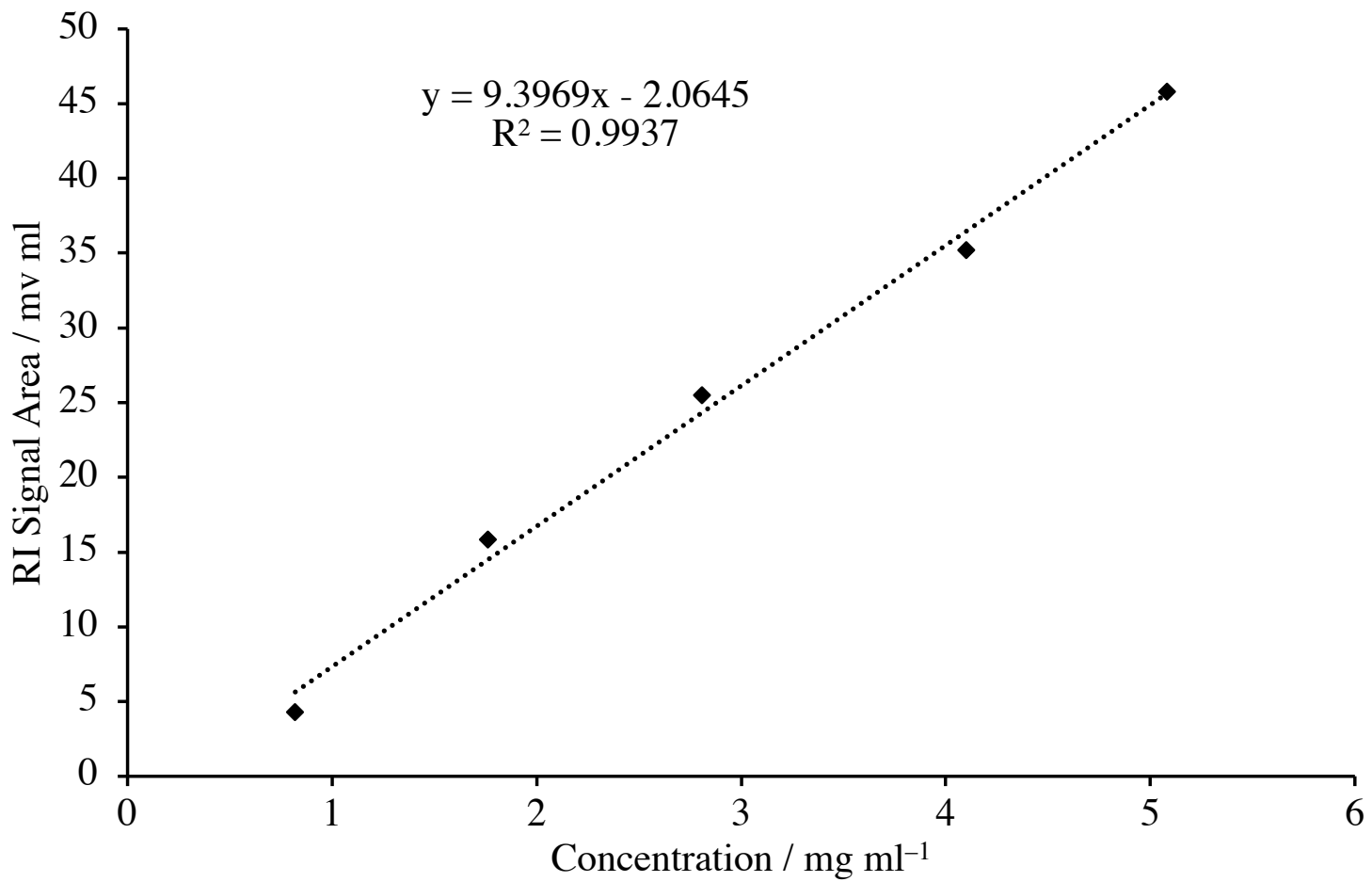

Figure S3: Change in the intensity of refractive index signal with concentration for a poly(LB-coMMA) 2 with $7 \mathrm{~mol} \%$ phosphine units, RI stands for refractive index.

Equation S1: The definition of refractive index signal intensity, where $\mathrm{K}_{\text {detector }}$ is the detector constant and $d n / d c$ is the refractive index.

$$
\text { Refrative index signal intensity }=K_{\text {Detector }} \cdot d n / d c_{\text {sample }} . \text { concentration }
$$

The calculation was performed from the known relationship provided in Equation S1. $\mathrm{K}_{\text {detector }}$ is calculated by preparing a precise concentration of a polymer with known refractive index (Equation S1) and this was determined to be $90.9 \mathrm{mv} \mathrm{ml}$ by using a standard polystyrene solution. Gradient of the line plotted in Figure $\mathrm{S} 3$ divided by $\mathrm{K}_{\text {detector }}$ gave a value of $0.103 \mathrm{ml} / \mathrm{mg}$ suggesting that even a small amount styrene-based monomer has significant effects on the $d n / d c$ value. 


\section{Section C: Shrinkage of the polymeric FLP networks}

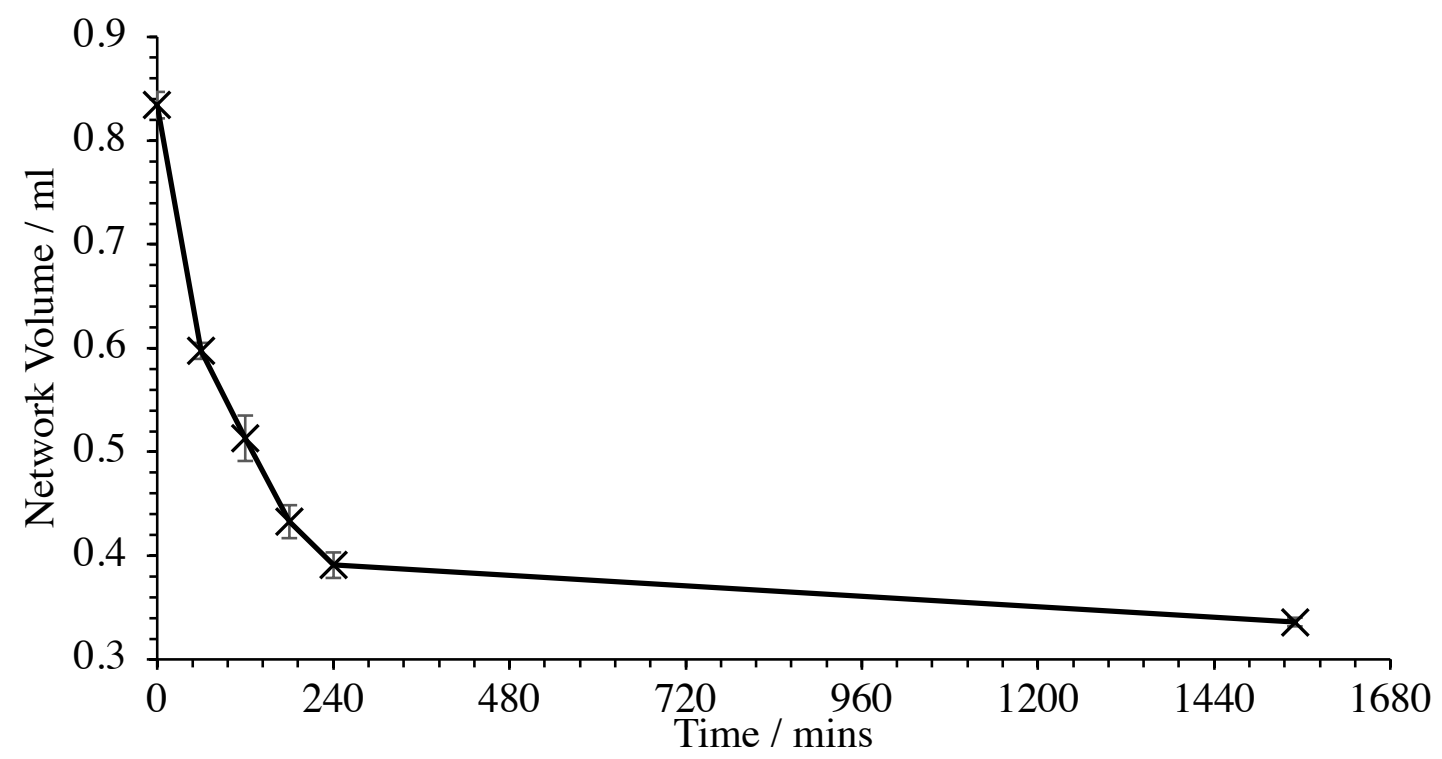

Figure S4: Change in the volume of the $7 \mathrm{~mol} \%$ crosslinking poly(MMA-co-FLP) network where $\mathrm{t}=0 \mathrm{~s}$ is when the crosslinker molecule was injected into mixture of the copolymers.

Section D: Supplementary rheology data and analysis

- Poly(MMA-co-FLP) 4 mol\% crosslinking network

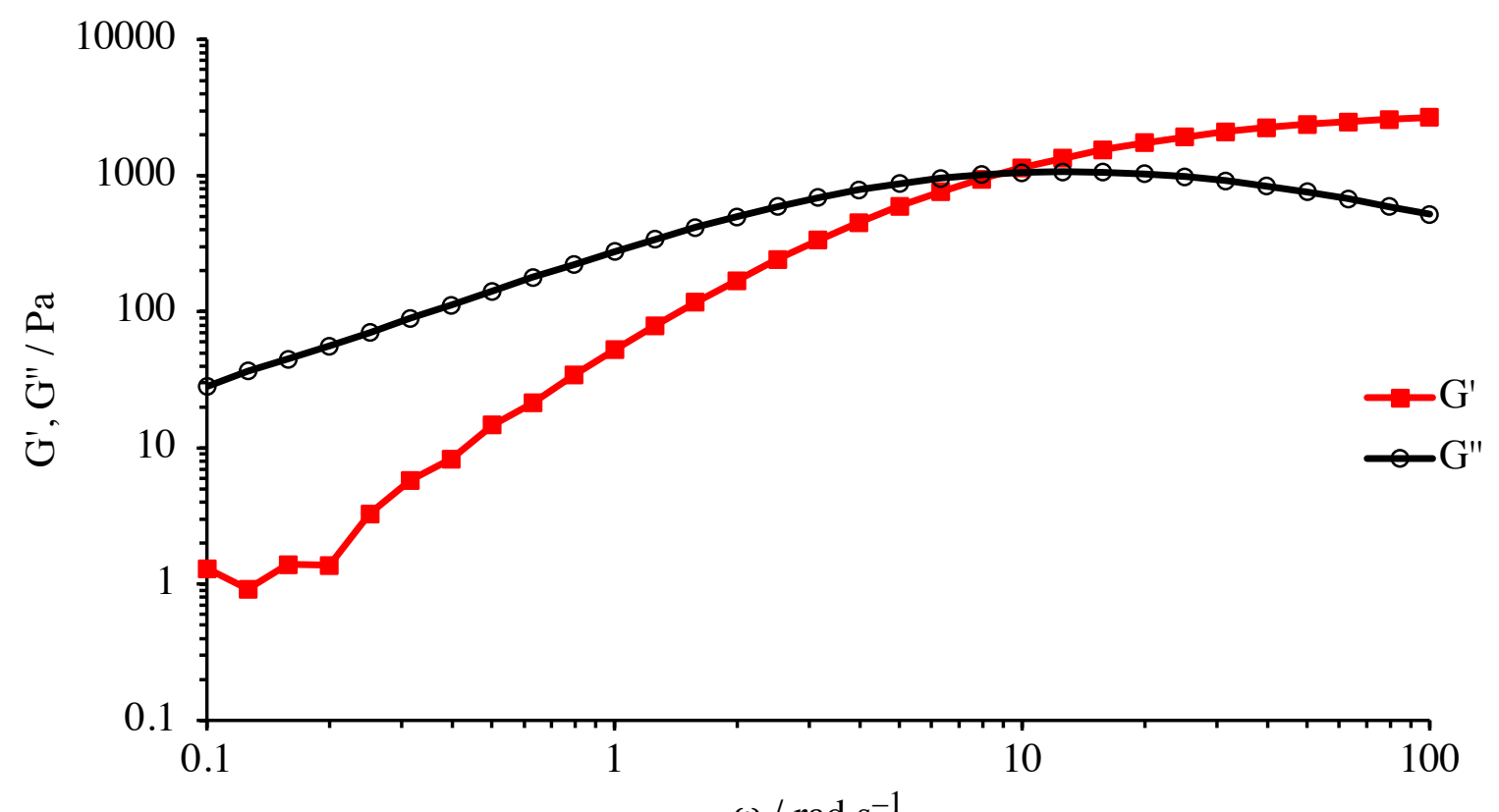

Figure S5: Frequency dependencies of the dynamic moduli of the 4 mol\% crosslinking MMA based polymeric FLP network at $20^{\circ} \mathrm{C}$ and $1 \%$ strain. 
No further characterization was performed with this gel as the two original macromolecules poly(MMA-co-LA) 1 and poly(MMA-co-LB) 1 appeared to be uncontrolled copolymers.

- Poly(sty-co-FLP) 4 mol\% crosslinking network At $0{ }^{\circ} \mathrm{C}$

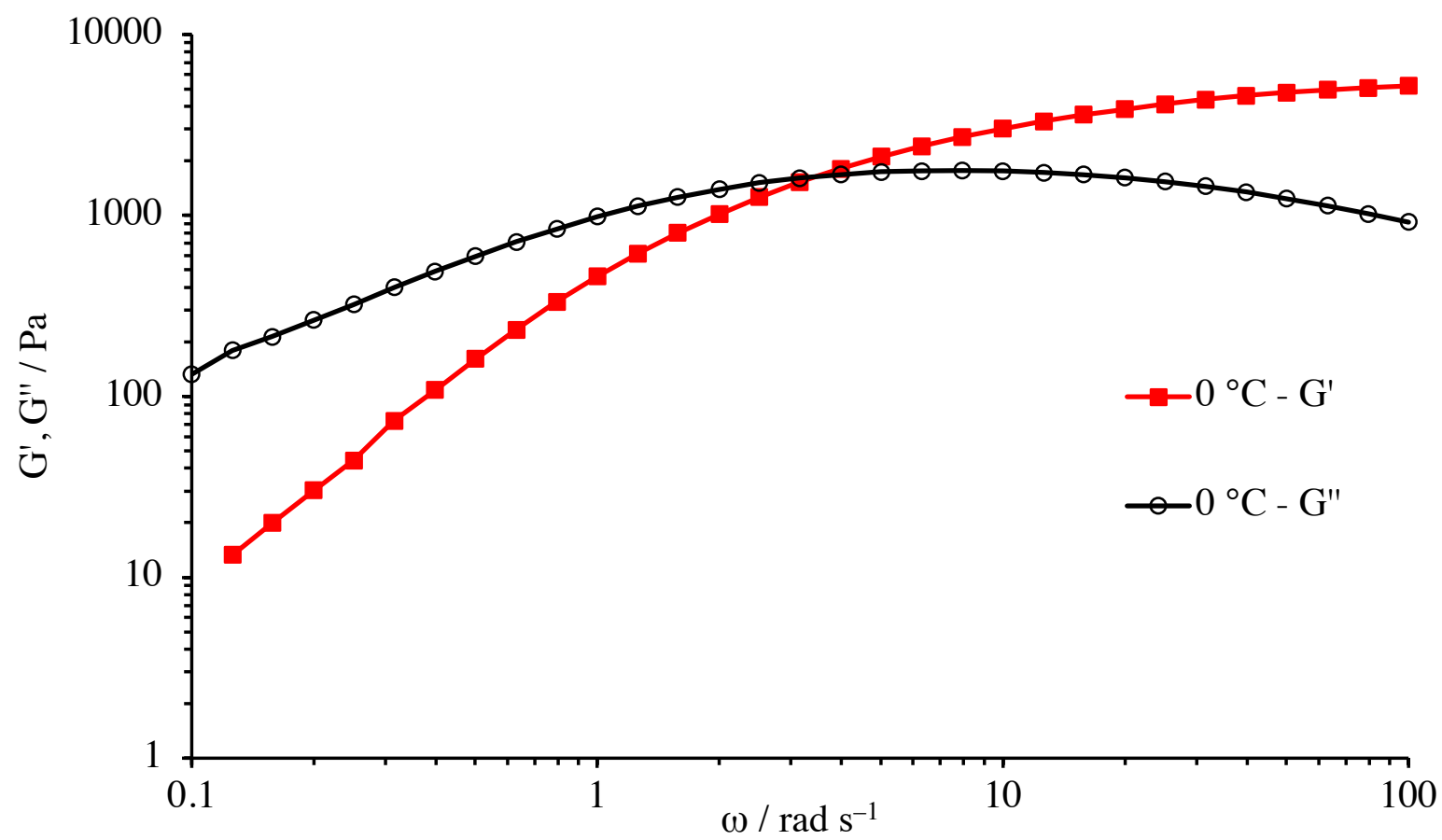

Figure S6: Frequency dependencies of the dynamic moduli of the 4 mol\% crosslinking Sty based polymeric FLP network at $1 \%$ strain. 
At $10{ }^{\circ} \mathrm{C}$

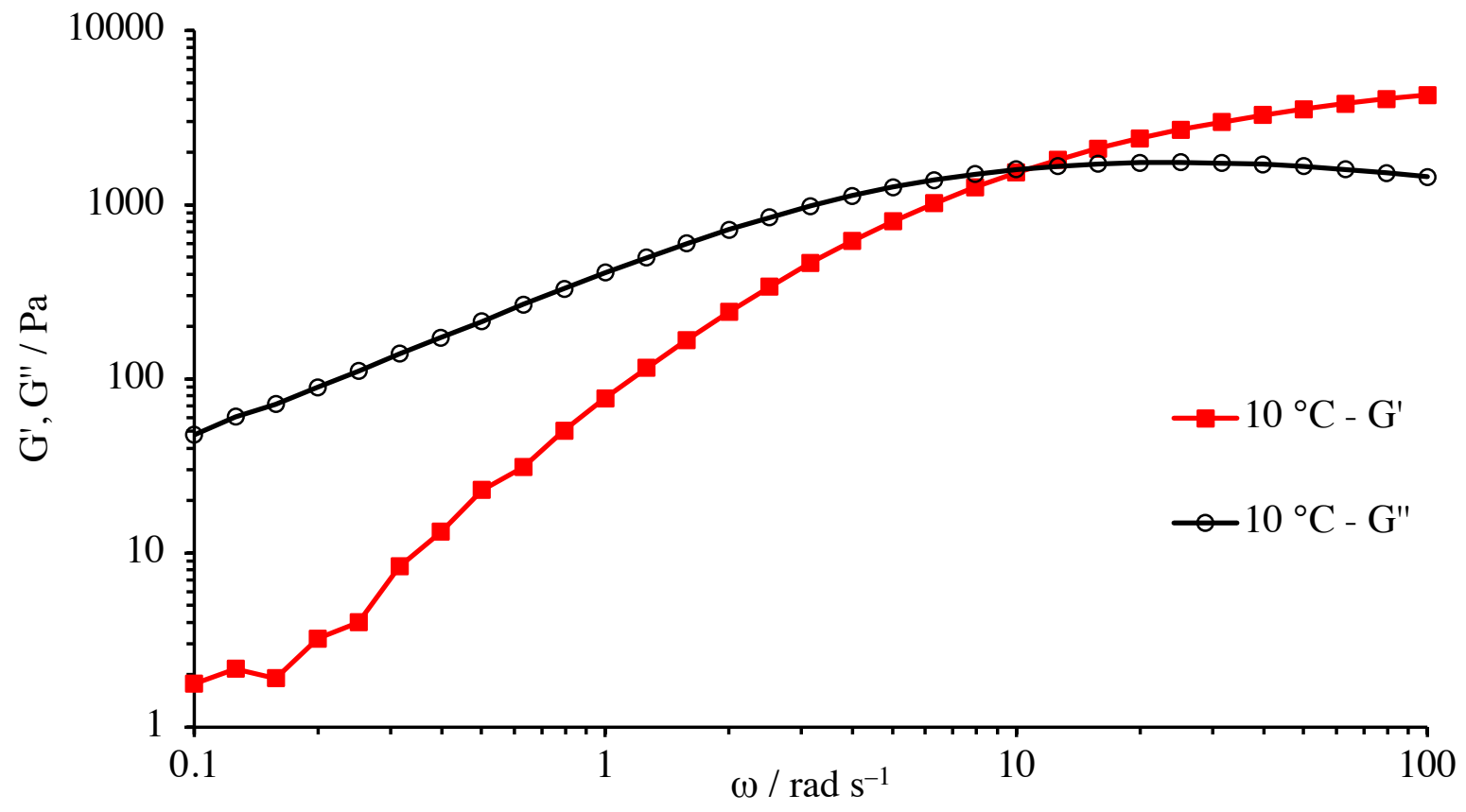

Figure S7: Frequency dependencies of the dynamic moduli of the 4 mol\% crosslinking Sty based polymeric FLP network at 1\% strain.

At $30{ }^{\circ} \mathrm{C}$

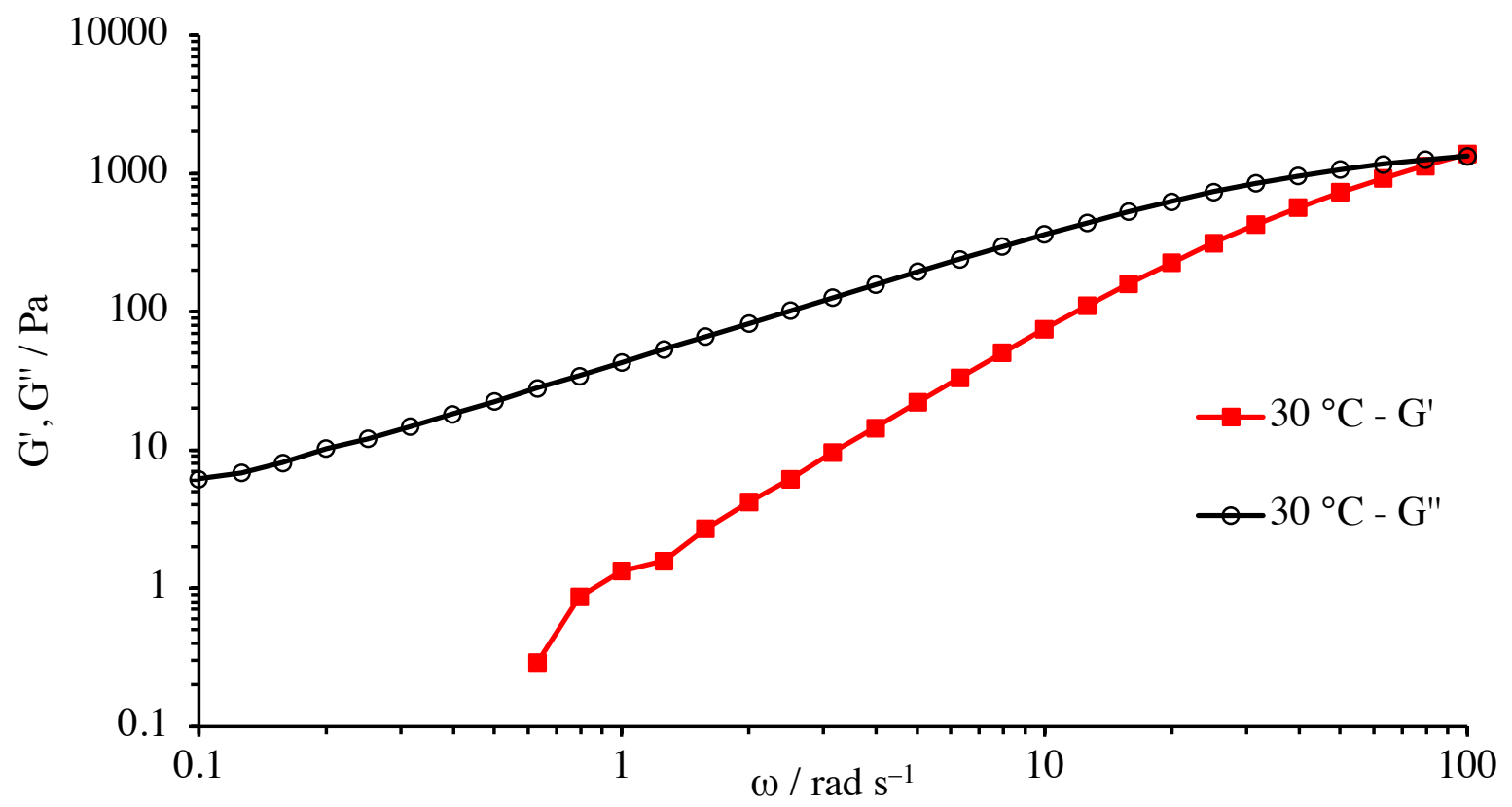

Figure S8: Frequency dependencies of the dynamic moduli of the 4 mol\% crosslinking Sty based polymeric FLP network at 1\% strain. 
At $40{ }^{\circ} \mathrm{C}$

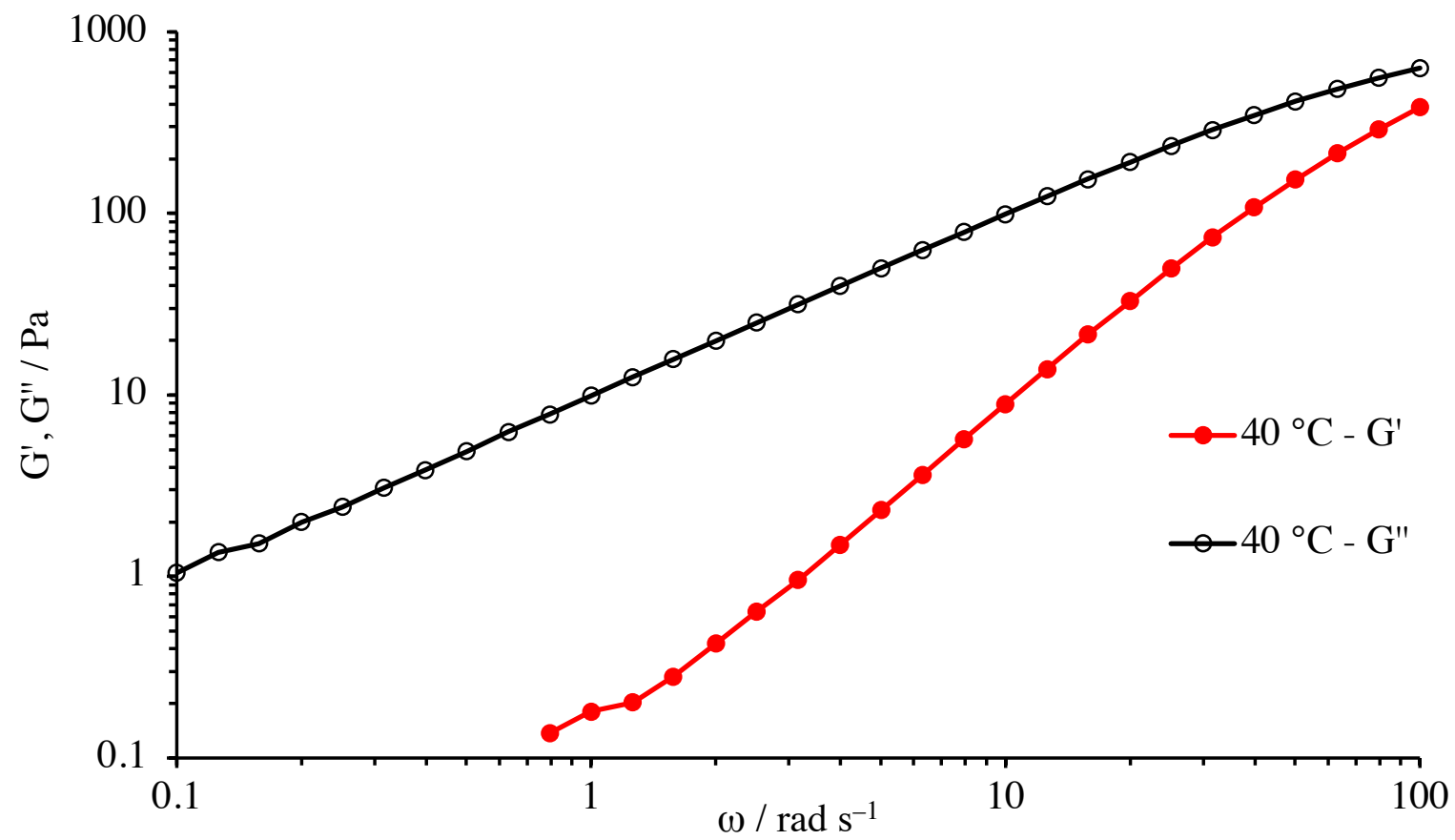

Figure S9: Frequency dependencies of the dynamic moduli of the $4 \mathrm{~mol} \%$ crosslinking Sty based polymeric FLP network at 1\% strain.

At $50{ }^{\circ} \mathrm{C}$

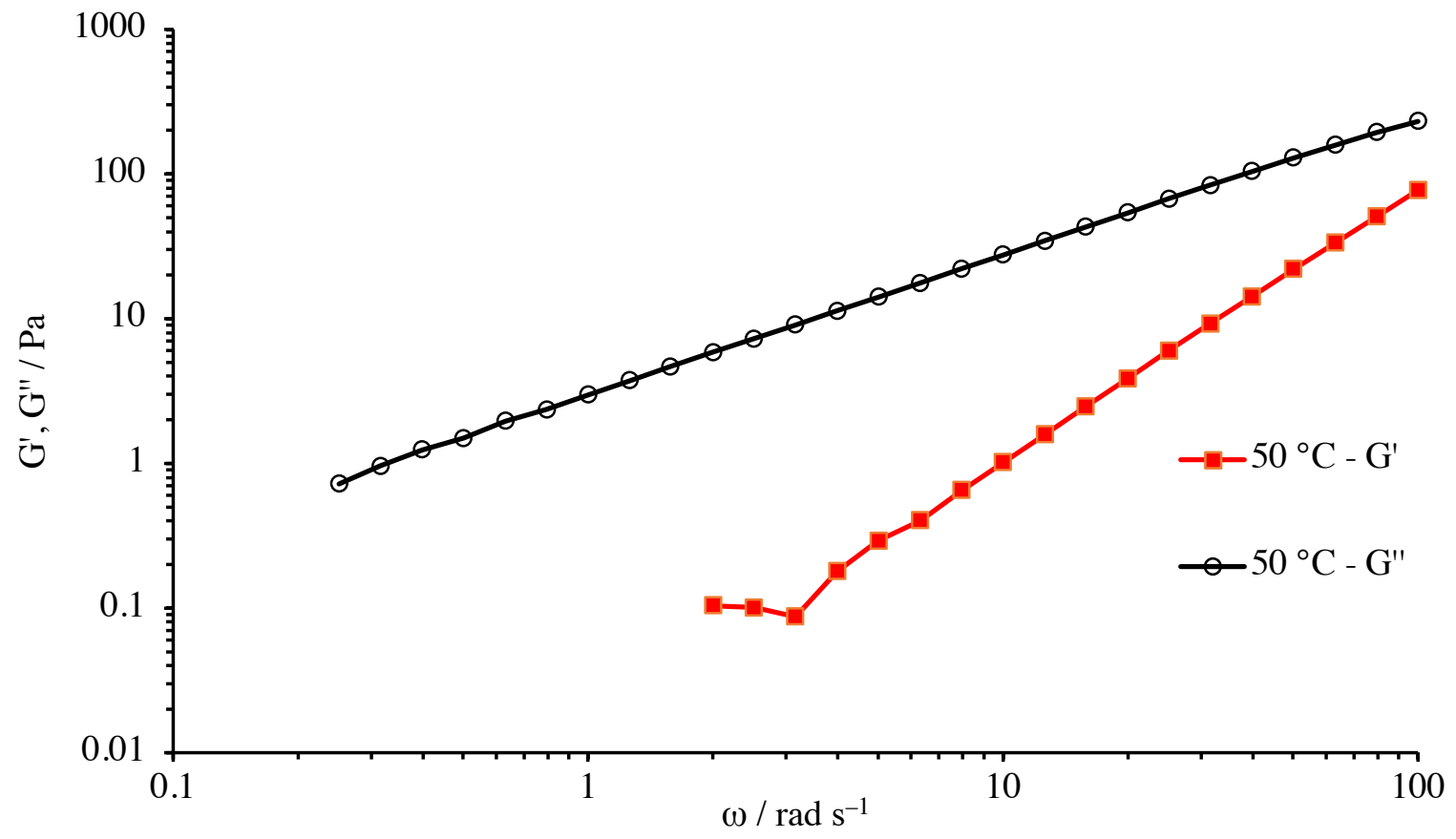

Figure S10: Frequency dependencies of the dynamic moduli of the $4 \mathrm{~mol} \%$ crosslinking Sty based polymeric FLP network at 1\% strain. 
Time-Temperature Superposition Master Curve

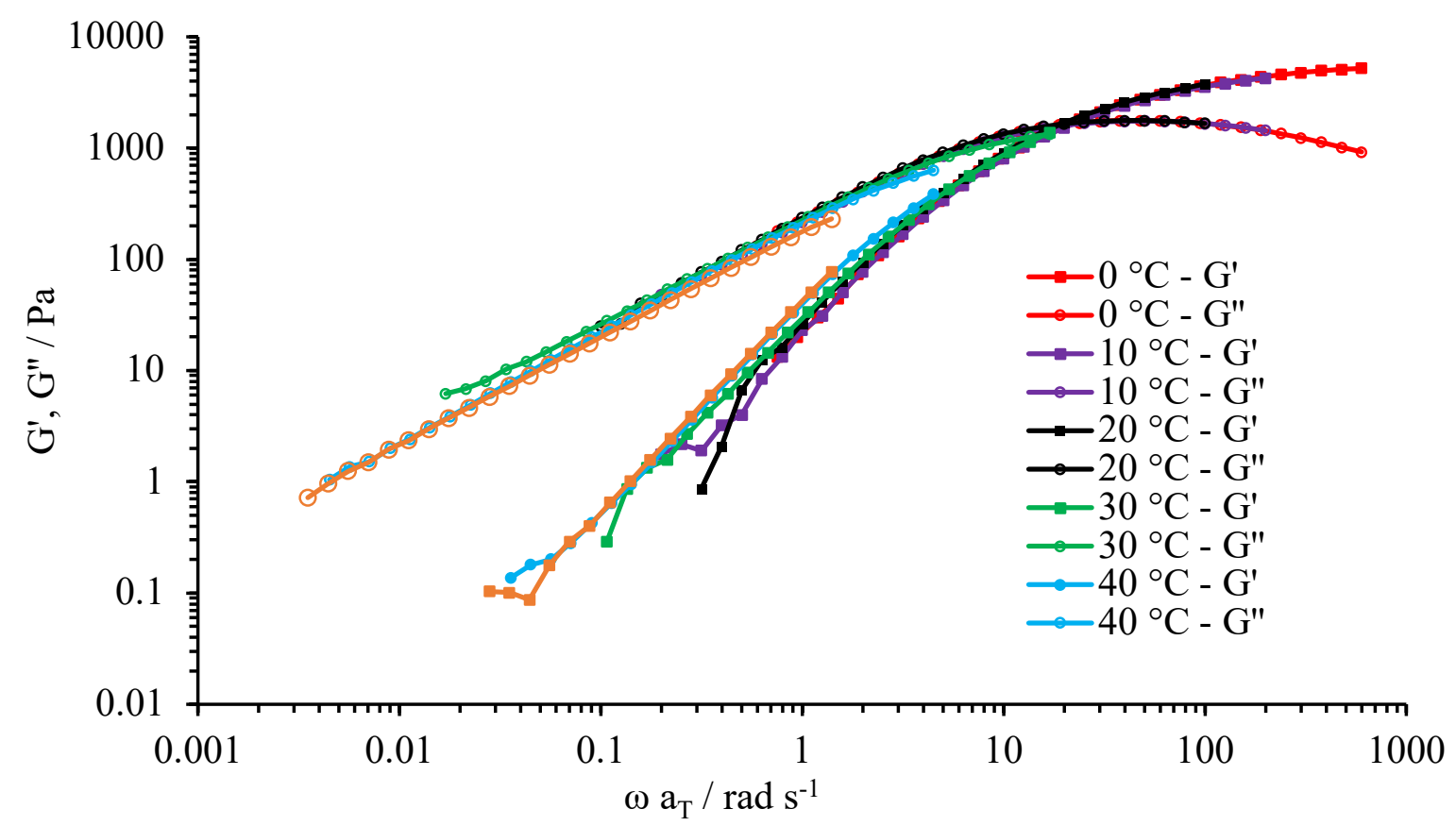

Figure S11: Time-temperature superposition master plot at reference temperature $20{ }^{\circ} \mathrm{C}$ for the 4 mol\% poly(sty-co-FLP) network.

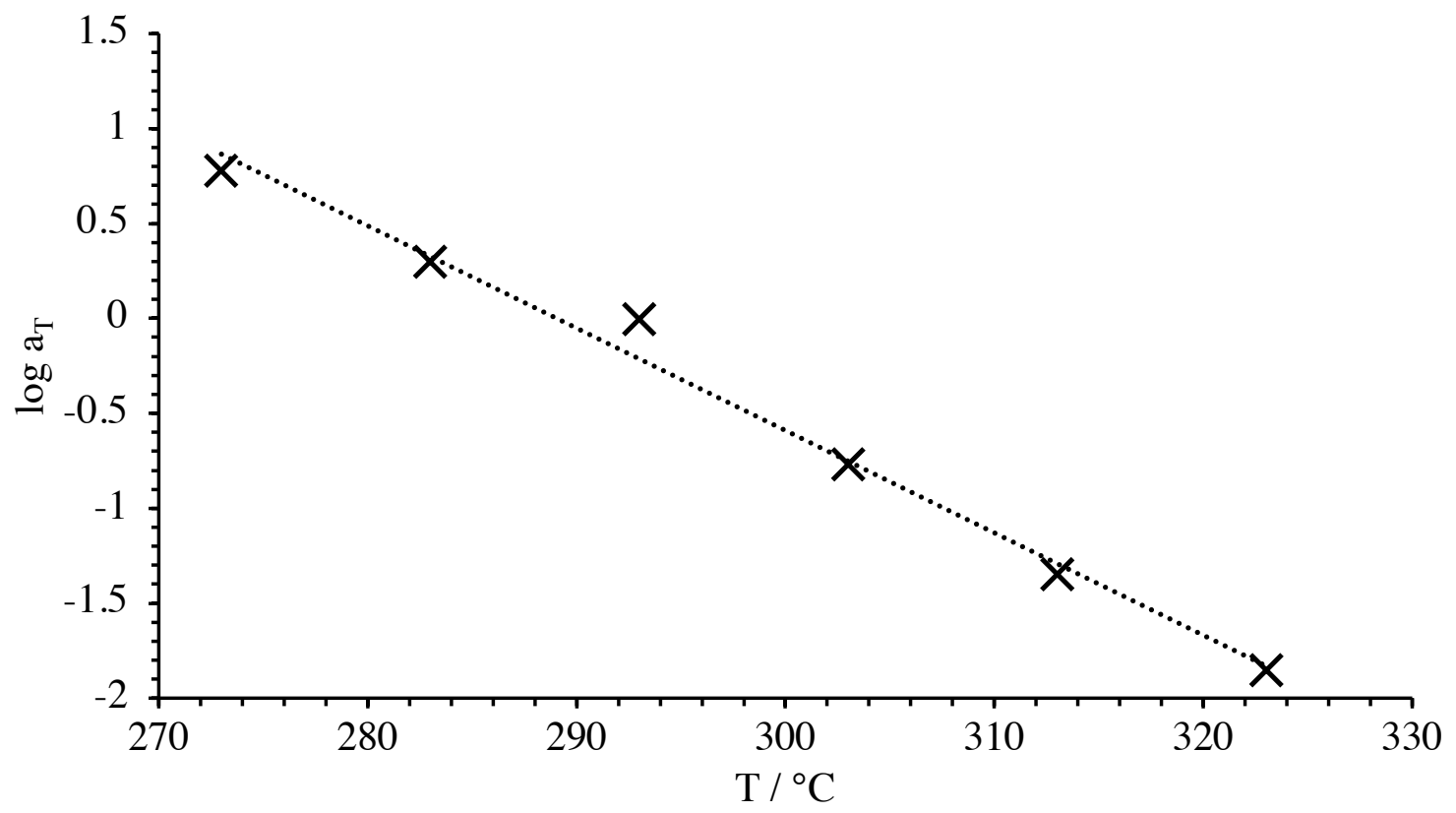

Figure S12: A plot to show how $\log \mathrm{a}_{\mathrm{T}}$ changes with temperature for the $4 \mathrm{~mol} \%$ poly(sty-coFLP) network. 


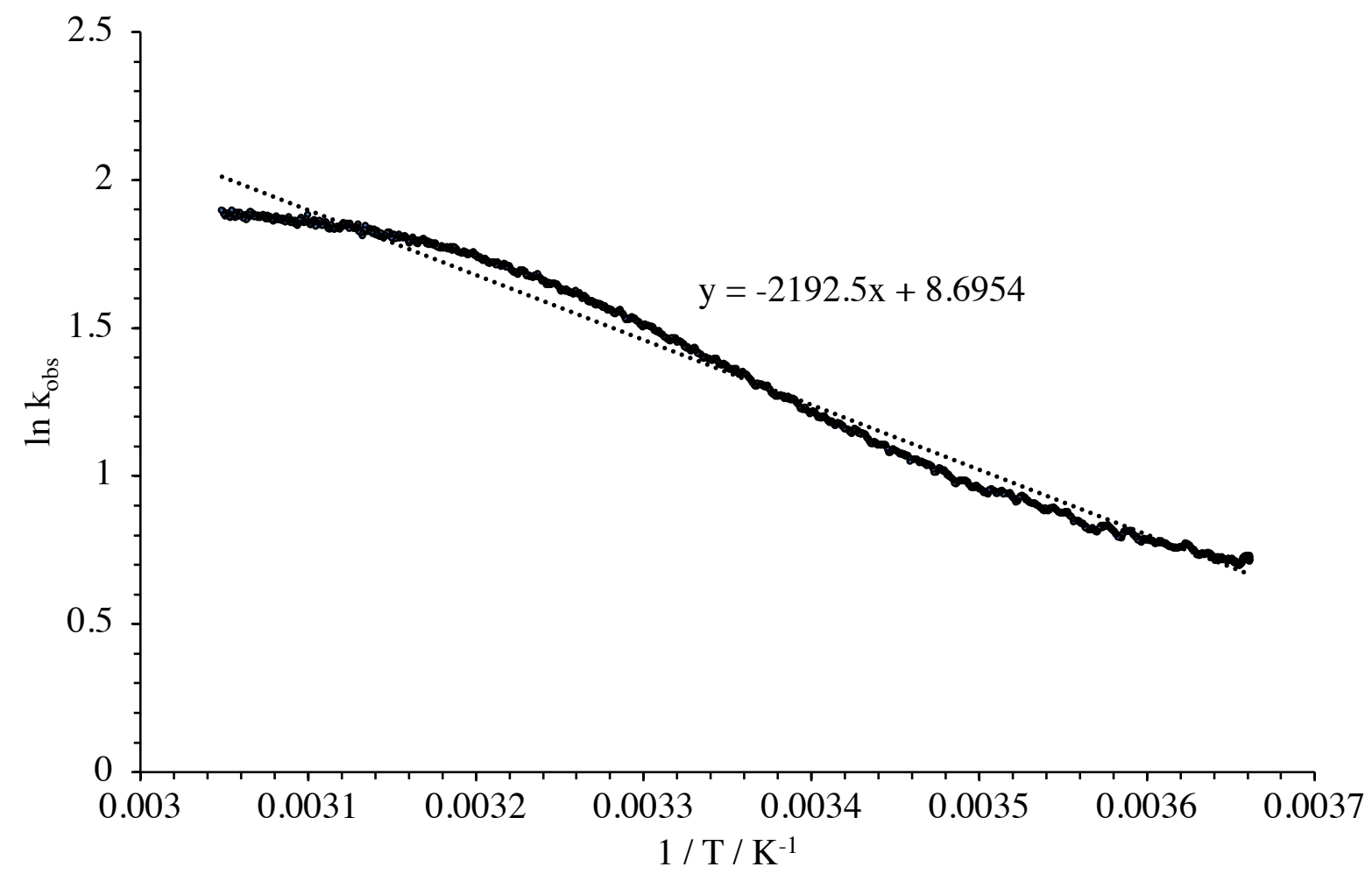

Figure S13: Arrhenius plot for the $4 \mathrm{~mol} \%$ crosslinked poly(sty-co-FLP) by using the $\mathrm{k}_{\mathrm{obs}}$ values obtained from the relaxation times calculated by applying the Maxwell model to the temperature sweep results.

\section{- Poly(sty/MMA-co-FLP) 7 mol\% crosslinking network}

At $0{ }^{\circ} \mathrm{C}$

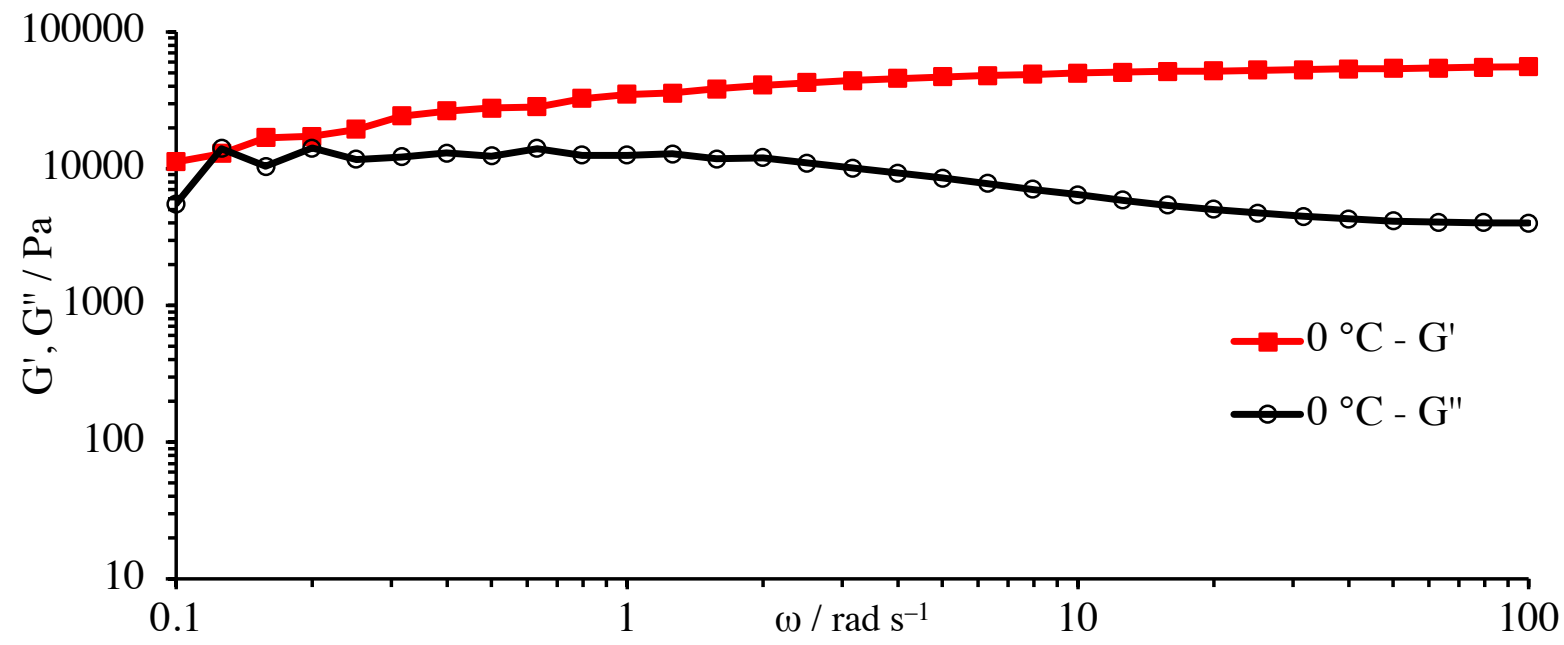

Figure S14: Frequency dependencies of the dynamic moduli of the $7 \mathrm{~mol} \%$ crosslinking mixed Sty/MMA based polymeric FLP network at $0.1 \%$ strain. 


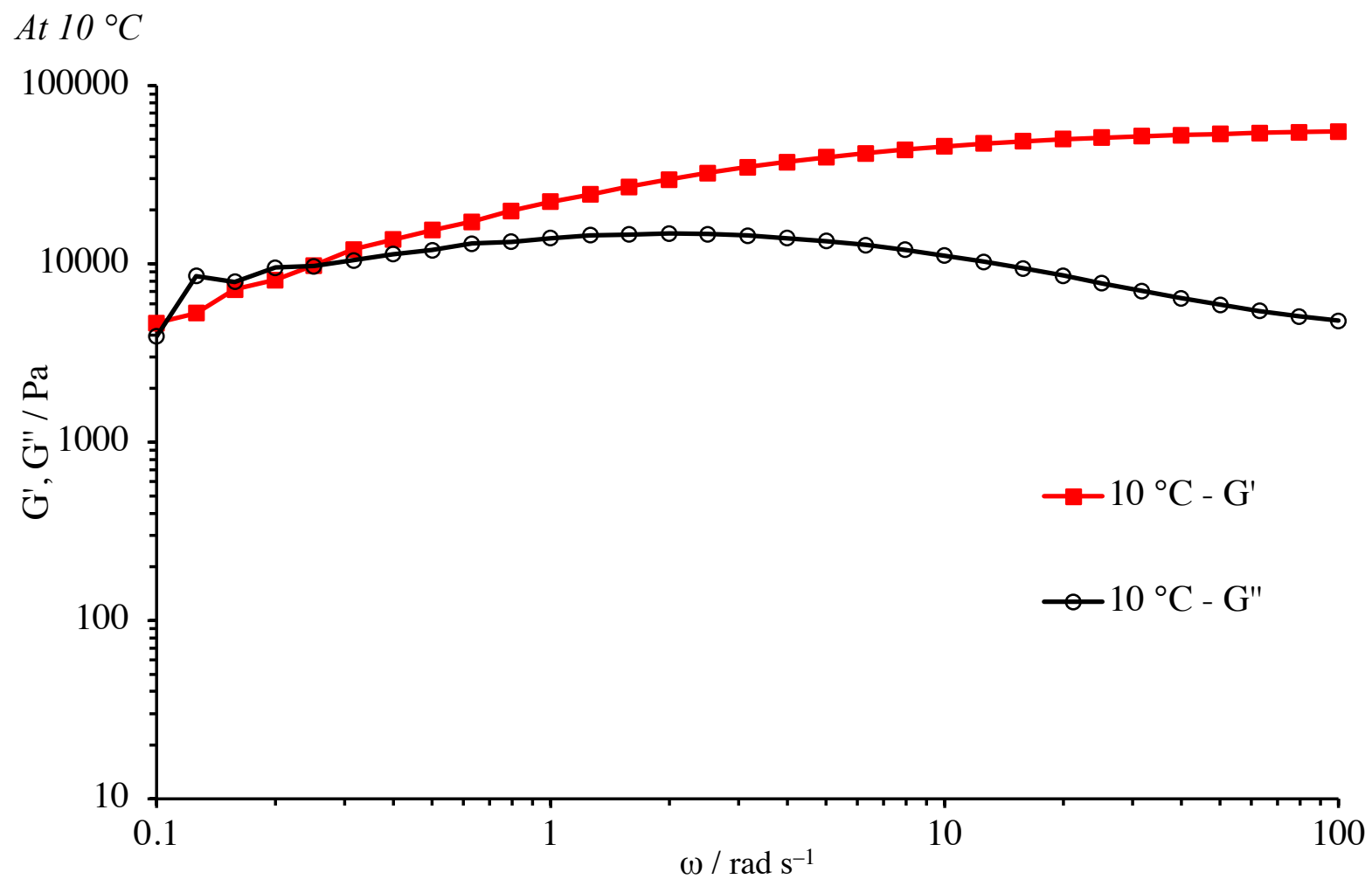

Figure S15: Frequency dependencies of the dynamic moduli of the 7 mol\% crosslinking mixed Sty/MMA based polymeric FLP network at $0.1 \%$ strain.

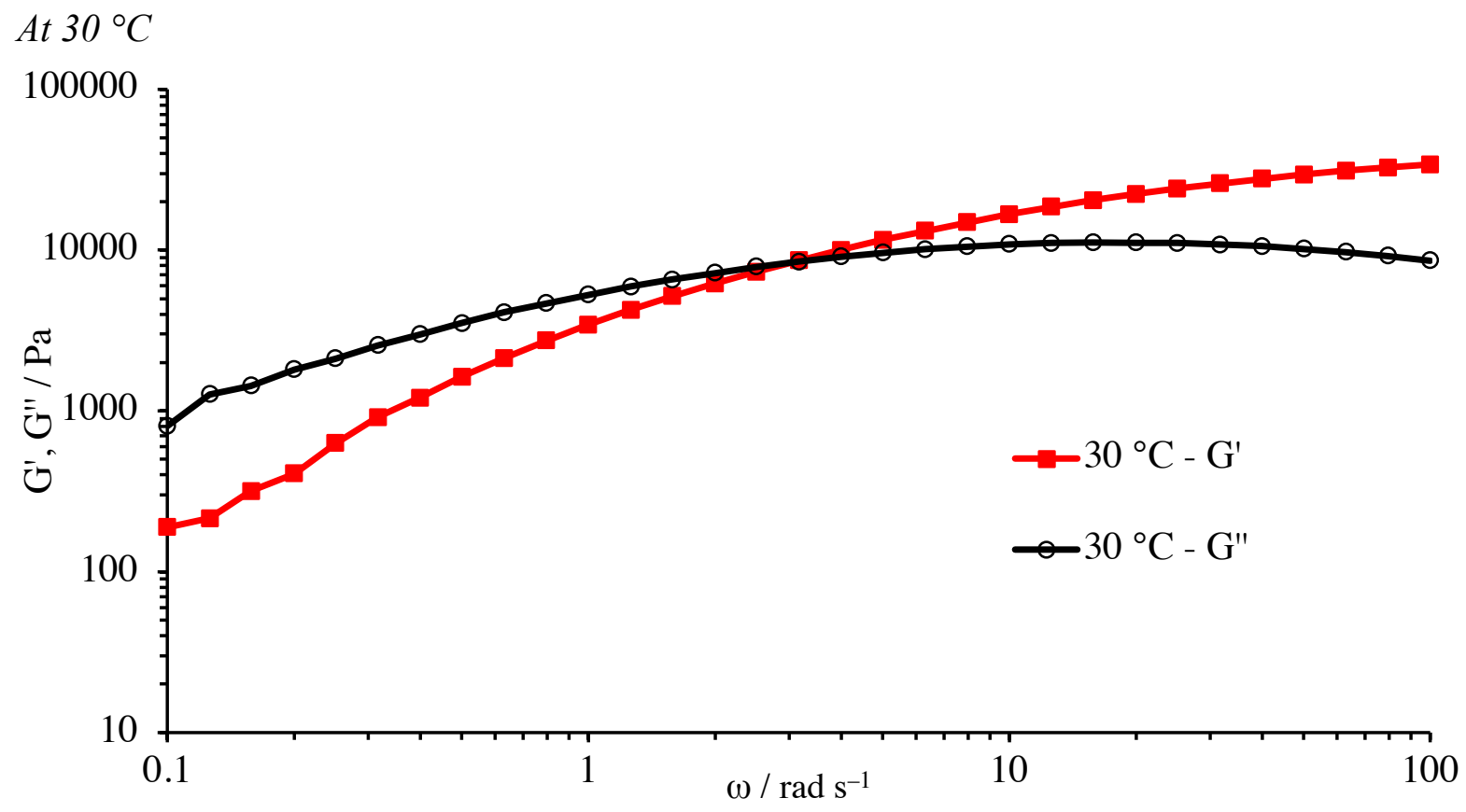

Figure S16: Frequency dependencies of the dynamic moduli of the $7 \mathrm{~mol} \%$ crosslinking mixed Sty/MMA based polymeric FLP network at $0.1 \%$ strain. 


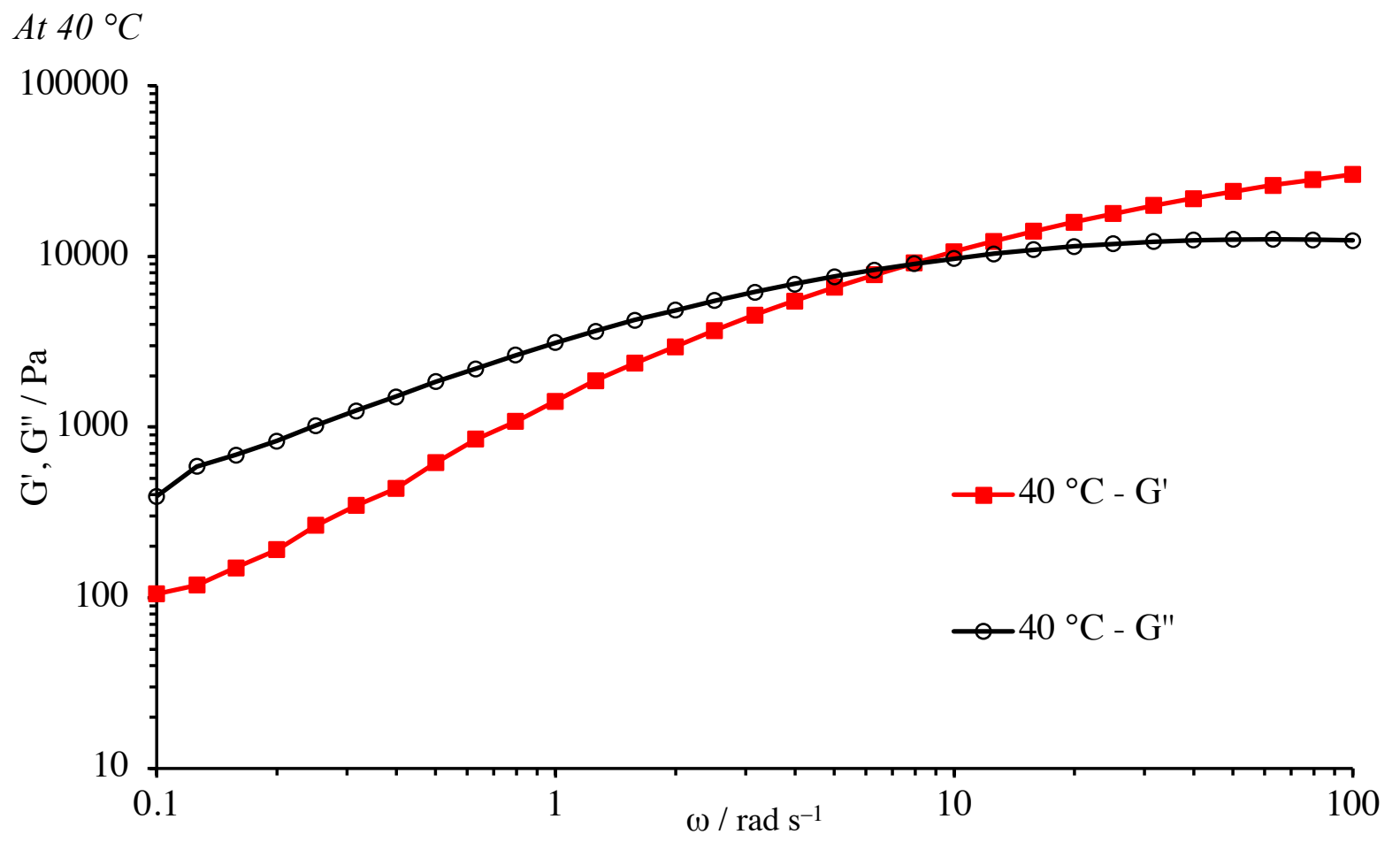

Figure S17: Frequency dependencies of the dynamic moduli of the $7 \mathrm{~mol} \%$ crosslinking mixed Sty/MMA based polymeric FLP network at $0.1 \%$ strain.

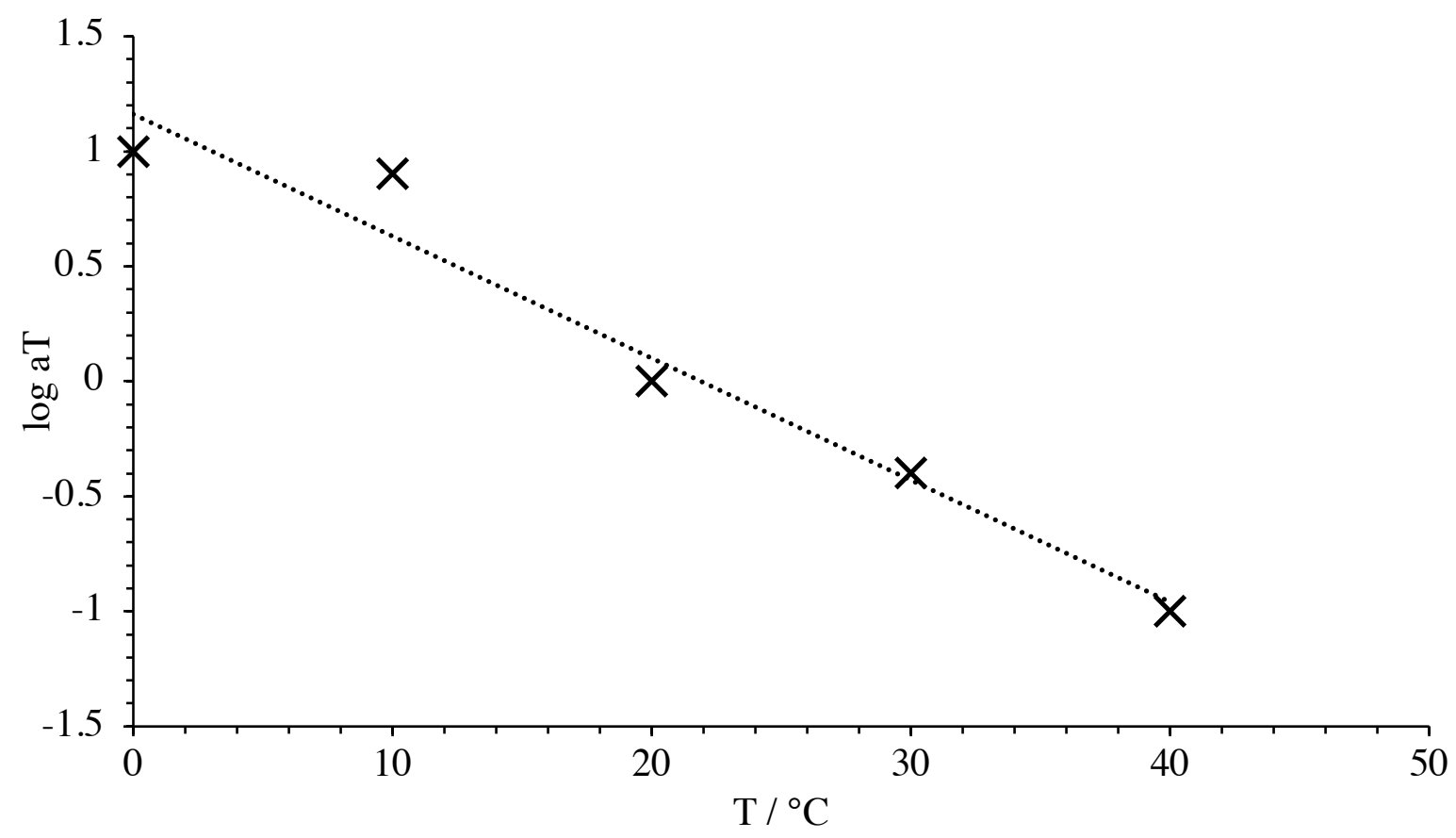

Figure S18: A plot to show how log aт changes with temperature for the $7 \mathrm{~mol} \%$ poly(sty/MMAco-FLP) network. 


\section{References}

1. Wang, M.; Nudelman, F.; Matthes, R. R.; Shaver, M. P. Frustrated Lewis Pair Polymers as

Responsive Self-Healing Gels. Journal of the American Chemical Society 2017, 139 (40), 1423214236 DOI: $10.1021 /$ jacs.7b07725. 